\author{
Marcelo E. Bigal \\ Richard B. Lipton
}

\section{The differential diagnosis of chronic daily headaches: an algorithm-based approach}

Received: 6 September 2007

Accepted in revised form: 19 September 2007

Published online: 25 October 2007

${ }^{0} 2007$ The Author ${ }^{1}$

M.E. Bigal (西) • R.B. Lipton

Department of Neurology,

Albert Einstein College of Medicine,

1300 Morris Park Avenue,

Rousso Bldg, Room 330,

Bronx, NY 10461, USA

Tel.: +1-718-430-3844

Fax: +1-718-430-3857

e-mail: mbigal@aecom.yu.edu

\section{R.B. Lipton}

Department of Epidemiology and

Population Health,

Albert Einstein College of Medicine,

Bronx, NY, USA

M.E. Bigal • R.B. Lipton

The Montefiore Headache Center,

Bronx, NY, USA

\author{
Abstract Chronic daily headaches \\ (CDHs) refers to primary \\ headaches that happen on at least \\ 15 days per month, for 4 or more \\ hours per day, for at least three \\ consecutive months. The differen- \\ tial diagnosis of CDHs is challeng- \\ ing and should proceed in an \\ orderly fashion. The approach \\ begins with a search for "red \\ flags" that suggest the possibility \\ of a secondary headache. If sec- \\ ondary headaches that mimic \\ $\mathrm{CDHs}$ are excluded, either on clin- \\ ical grounds or through investiga- \\ tion, the next step is to classify the \\ headaches based on the duration of \\ attacks. If the attacks last less than \\ 4 hours per day, a trigeminal auto- \\ nomic cephalalgia (TAC) is likely. \\ TACs include episodic and chronic \\ cluster headache, episodic and \\ chronic paroxysmal hemicrania, \\ SUNCT, and hypnic headache. If
}

the duration is $\geq 4 \mathrm{~h}$, a $\mathrm{CDH}$ is likely and the differential diagnosis encompasses chronic migraine, chronic tension-type headache, new daily persistent headache and hemicrania continua. The clinical approach to diagnosing $\mathrm{CDH}$ is the scope of this review.

Keywords Chronic daily headache • Differential diagnosis $\cdot$ Strategy

\section{Introduction}

Chronic daily headaches $(\mathrm{CDH})$ may be broadly or narrowly defined. In the broad sense, $\mathrm{CDH}$ encompasses all headaches that occur on 15 days per month or more. They are subdivided in primary CDHs (not caused by other disorders) and secondary CDHs (there is an underlying cause such as infection or tumour). The primary CDHs are further subdivided into those of long duration ( $\geq 4 \mathrm{~h}$ a day) and shorter duration ( $<4$ h duration) [1-3].

In its narrow and more frequently used sense, $\mathrm{CDH}$ is

${ }^{1}$ This is a "Springer Open Choice" article. Unrestricted non-commercial use, distribution, and reproduction in any medium is permitted, provided the original author and source are credited. 
used to refer exclusively to "primary $\mathrm{CDH}$ of long duration", a clinical syndrome defined by headaches that occur for $\geq 4 \mathrm{~h}$ a day on $\geq 15$ days a month over $>3$ months in individuals without an underlying cause [1]. Unless otherwise indicated, in this paper, $\mathrm{CDH}$ refers to primary $\mathrm{CDHs}$ of long duration.

$\mathrm{CDH}$ is the third most common primary headache in the population, with an overall prevalence ranging from $4 \%$ to $5 \%[4,5]$. Because of their frequency, severity and duration, $\mathrm{CDH}$ are extraordinarily burdensome to individuals and society. Furthermore, $\mathrm{CDH}$ is the most common reason for consultation in headache clinics.

The Silberstein and Lipton (S-L) criteria for $\mathrm{CDH}$ and its subtypes have been widely used and are well accepted [1]. According to these criteria, $\mathrm{CDH}$ is divided into four groups: chronic or transformed migraine (CM/TM), chronic tensiontype headache (CTTH), new daily persistent headache (NDPH) and hemicrania continua (HC), and subclassified into subtypes with medication overuse or without medication overuse, incorporating the concept that medication overuse is often associated with the onset of $\mathrm{CDH}$.

The differential diagnosis of $\mathrm{CDHs}$ is challenging and should proceed in an orderly fashion. Crucial elements include a thorough history, supplemented by general medical and neurological examinations, as well as laboratory testing and neuroimaging in selected patients. Herein we discuss the strategy to diagnose CDHs and their differential diagnosis. We emphasise that this strategy reflects the authors' personal view of CDHs, as well as our personal diagnostic experience. Furthermore, the diagnostic algorithms presented herein have not been validated.

\section{First step: distinguishing primary from secondary CDH}

An important first step in headache diagnosis is to distinguish primary from secondary $\mathrm{CDH}$. The detailed strategies to identify or exclude secondary headaches are beyond the scope of this paper. In brief, the approach begins with a search for "red flags" that suggest the possibility of a secondary headache (Fig. 1). Once these features are identified, the physician must conduct the appropriate work-up to identify or exclude the conditions suggested by the red flag (Table 1). Once secondary headache is excluded by history, physical and neurological examination and/or appropriate testing, the next step is to diagnose the primary headache disorder [6].

Many patients with red flags do not have secondary headache disorders. Nonetheless, when red flags are present, they often merit investigation. Red flags include: (1) sudden onset of a severe headache; (2) a worsening pattern of a preexisting headache in the absence of obvious predisposing factors (e.g. medication overuse, depression); (3) headache with cancer, HIV or other systemic illness (fever, neck stiffness, cutaneous rash); (4) headache associated

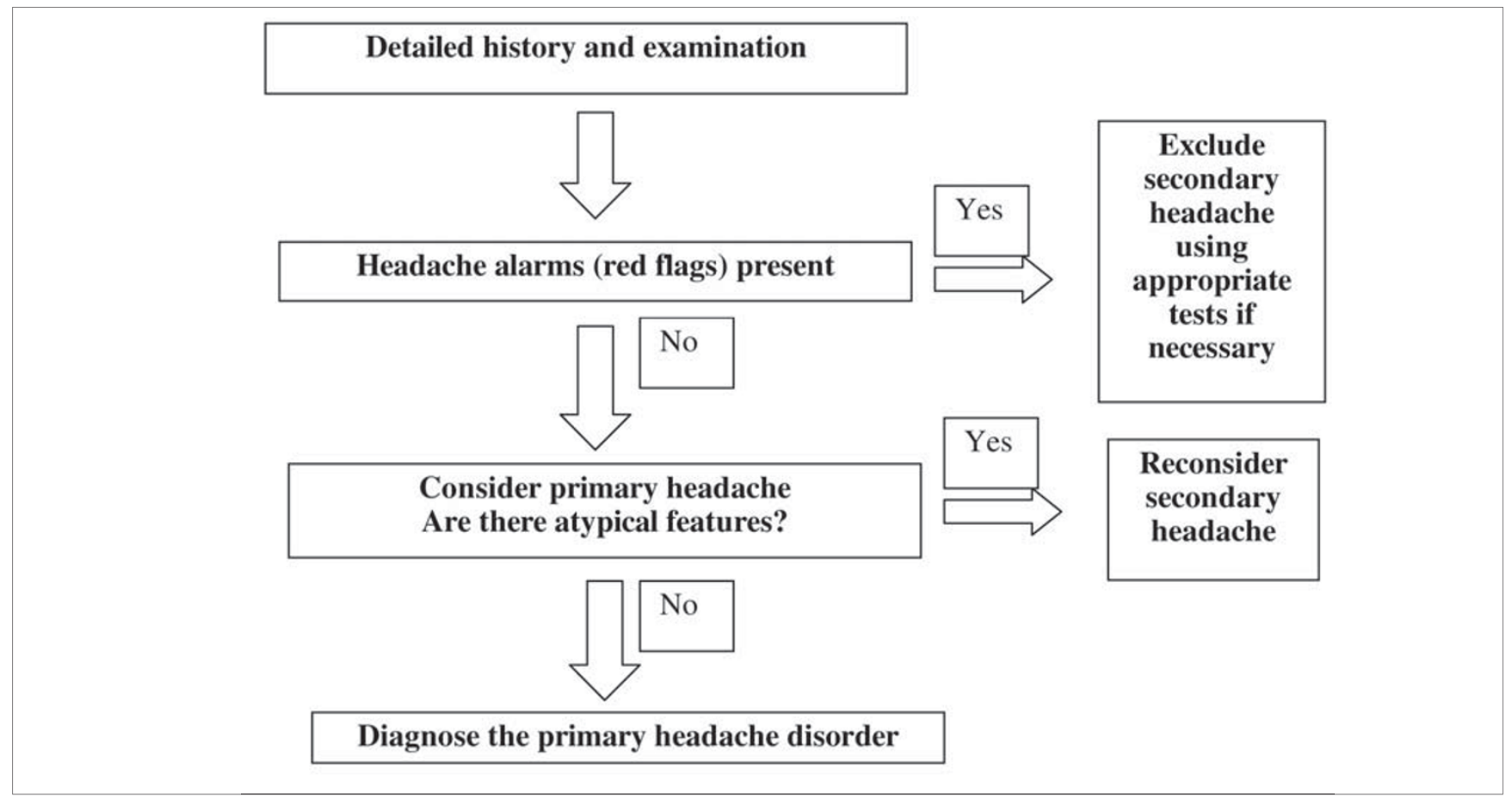

Fig. 1 Algorithm for headache diagnosis. Modified from [25] 
with focal neurologic signs other than typical visual or sensory aura; (5) headache in a patient with papilloedema; (6) moderate or severe headache triggered by cough, exertion, orgasm or Valsalva; and (7) new onset of a headache during pregnancy or post-partum.

Other less common secondary causes of intractable headache that may lead to $\mathrm{CDH}$ are summarised in Table 2. Detection of many of these disorders requires a systematic approach to the headache history and physical examination as well as a high index of suspicion. We will highlight some of these critical issues. For a review on this topic, the reader is referred to [7].

Red flags triggered by the temporal profile of headache

The temporal profile of the headache, and its nature and the circumstances of its onset are crucial for diagnosis. The temporal profile of a headache can provide important clues to its aetiology. A few examples are listed below:

- A rapid-onset headache may suggest a subarachnoid haemorrhage, pituitary apoplexy [8] or other intracranial catastrophes [9]. These disorders rarely cause $\mathrm{CDH}$, but can result in intractability of an ongoing headache attack.

Table 1 Red flags in the diagnosis of headache. Modified from [6]

\begin{tabular}{|c|c|c|}
\hline Red flag & Consider & Possible investigation(s) \\
\hline Sudden-onset headache & $\begin{array}{l}\text { Subarachnoid haemorrhage, bleed into a mass } \\
\text { or AVM, mass lesion (especially posterior fossa) }\end{array}$ & $\begin{array}{l}\text { Neuroimaging, lumbar puncture } \\
\text { (after neuroimaging evaluation) }\end{array}$ \\
\hline Worsening-pattern headache & Mass lesion, subdural haematoma, medication overuse & Neuroimaging \\
\hline $\begin{array}{l}\text { Headache with cancer, HIV or other } \\
\text { systemic illness (fever, neck stiffness, } \\
\text { cutaneous rash) }\end{array}$ & $\begin{array}{l}\text { Meningitis, encephalitis, Lyme disease, systemic } \\
\text { infection, collagen vascular disease, arteritis }\end{array}$ & $\begin{array}{l}\text { Neuroimaging, lumbar puncture, biopsy, } \\
\text { blood tests }\end{array}$ \\
\hline $\begin{array}{l}\text { Focal neurologic signs, or symptoms } \\
\text { other than typical visual or sensory aura }\end{array}$ & Mass lesion, AVM, collagen vascular disease & $\begin{array}{l}\text { Neuroimaging, collagen vascular } \\
\text { evaluation }\end{array}$ \\
\hline Papilloedema & Mass lesion, pseudotumour, encephalitis, meningitis & $\begin{array}{l}\text { Neuroimaging, lumbar puncture } \\
\text { (after neuroimaging evaluation) }\end{array}$ \\
\hline Triggered by cough, exertion or Valsalva & Subarachnoid haemorrhage, mass lesion & $\begin{array}{l}\text { Neuroimaging, consider lumbar } \\
\text { puncture }\end{array}$ \\
\hline Headache during pregnancy or post-partum & $\begin{array}{l}\text { Cortical vein/cranial sinus thrombosis, carotid } \\
\text { dissection, pituitary apoplexy }\end{array}$ & Neuroimaging \\
\hline
\end{tabular}

Table 2 Secondary headaches that mimic chronic benign headache syndromes

Headache associated with vascular disorders

Cerebrovascular disease including carotid artery dissection and arteriovenous malformation

Arteritis including giant cell arteritis

Headache associated with non-vascular intracranial disorders

Low CSF pressure syndrome (spontaneous or post-traumatic CSF "leak")

High CSF pressure without papilloedema

Intracranial: Lyme disease, human immunodeficiency virus, encephalitis, fungal meningitis, etc.

Headache associated with substances or their withdrawal

Overuse of acute headache medications (rebound or toxic drug overuse syndromes)

Headache associated with cranium, neck, eyes, ears, nose, sinuses, teeth, mouth or other facial or cranial structures

Otolaryngologic disease, including chronic sphenoid sinusitis (or other sinus disease)

Nasopharyngeal disorders, including carcinoma

Disorders of the trigeminal nerve, including dental and oral disease, jaw pathology

Subacute angle closure glaucoma, optic neuritis and other ocular disorders

Occipitocervical disease, including Arnold-Chiari Malformation Type I; upper cervical joint, root or nerve (neuralgic) syndromes

Headache associated with non-cephalic infection, metabolic or systemic disturbances

Hepatitis, renal disease, $\mathrm{B}_{12}$ deficiency, anaemia, exposure to carbon monoxide and other toxins

Hormonal disturbances/endocrinologic disease (oestrogen, thyroid disease, hyperprolactinaemia, etc.)

Vasculitis/rheumatic/connective tissue disorders

Miscellanea

Mediastinal and thoracic processes including angina, mass lesions, superior vena cava syndrome 
- Sphenoid sinusitis may cause NDPH and may be missed radiologically unless appropriate studies are performed [10].

- Headaches that start after age 55 suggest an organic disorder for $\mathrm{CDH}$, such as a mass lesion or giant cell arteritis [11]. Giant cell arteritis is often under-diagnosed, and is an important cause of preventable blindness in the elderly.

Red flags triggered by concurrent events or provoking activity

Concurrent events and headache triggers may give clues to diagnosis, and some of them are listed below:

- Chronic headaches (NDPH) that occur in the peripartum period may be due to dural sinus thrombosis [12].

- Orthostatic CDH suggests a low CSF pressure headache (from a spontaneous CSF leak, a previous lumbar puncture, or an epidural block) [13].

- $\mathrm{CDH}$ exacerbated by straining, coughing or sneezing suggests a hindbrain malformation, occipitocervical junction disorder or increased intracranial pressure [14].

- $\mathrm{CDH}$ that is worse in the morning in the absence of medication overuse, that may suggest raised intracranial pressure. CDH with medication overuse is often worse in the morning.

- In contrast, subjects with $\mathrm{CDH}$ that is better in the morning and worse at night that may suggest low CSF volume headache [13].

- Similarly, CDHs that are worse on awakening sometimes occur with obstructive sleep apnoea [13].

- Increasing pain while upright, and neck pain and headache provoked by flexion or extension of the neck might suggest an occipitocervical junction disorder or a systemic medical illness [15-17].

- Search for opportunistic infections, including toxoplas- mosis and cryptococcal meningitis, in patients who may have HIV infection or HIV risk factors [18].

- A previous mild to moderate head or neck injury is frequently overlooked in the standard history, despite the fact that it can render an individual refractory to standard headache treatments [19]. A diagnosis of post-traumatic headache may lead to additional treatment including trigger point injections and facet joint and cervical nerve blocks.

- The history often neglects recent dental procedures. Root canals, tooth extractions or bite disturbances may provoke or be associated with the development of $\mathrm{CDH}$ due to brain abscess [20, 21].

- Consider ocular disturbances, such as subacute angle closure glaucoma, or infection, if the $\mathrm{CDH}$ is worse in the periorbital region [22].

- Nasal blockage, drainage, pus or pressure may suggest sinus disease [23]. Nasopharyngeal carcinoma can produce chronic head and face pain and can be identified by detailed, expert examination of the nasopharynx or neuroimaging [24].

In the absence of secondary $\mathrm{CDH}$, the clinician proceeds to diagnose a primary $\mathrm{CDH}$ disorder. If the headache is atypical or difficult to classify, the possibility of secondary headache should be reconsidered, although the modifying effect of any treatment being taken should be kept in mind. Additionally, lack of response to appropriate treatment given for enough time may also be considered a red flag.

\section{Second step: classifying primary CDH based on duration and frequency (Fig. 2)}

Basically, in a patient where we excluded, either by clini-

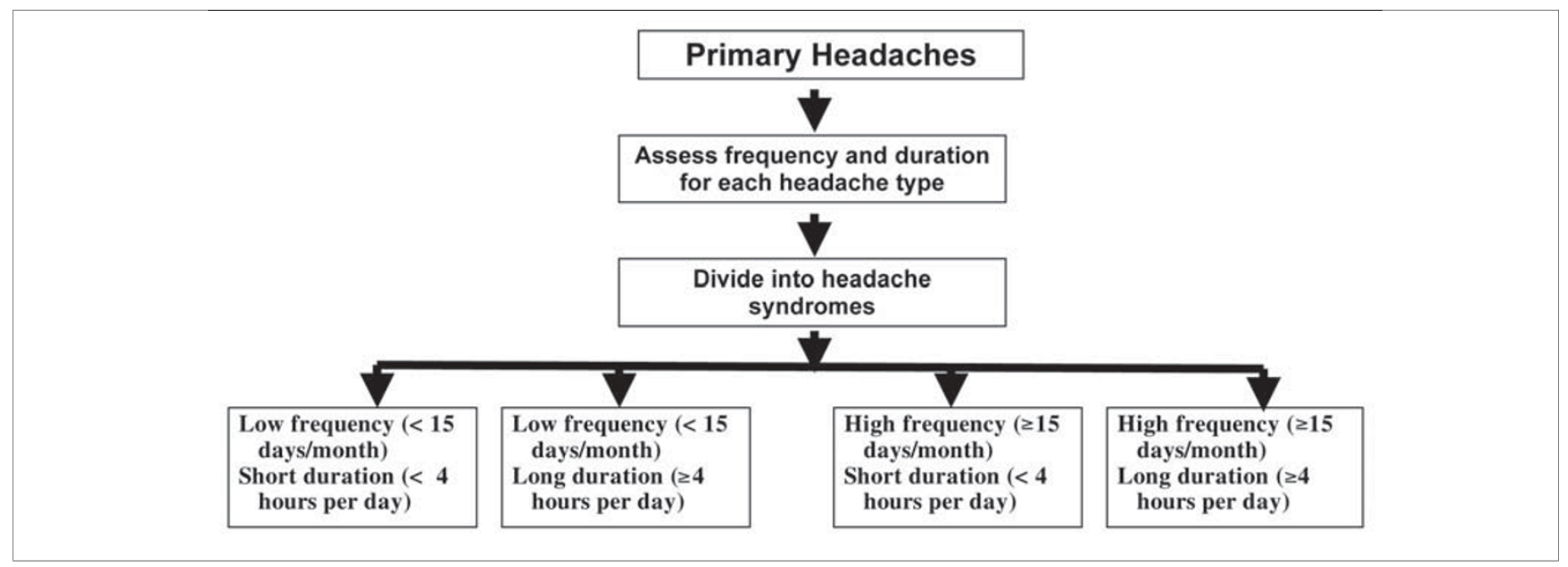

Fig. 2 Algorithm for classifying primary headaches based on frequency and duration 
cal history or by appropriate investigation, secondary headache syndromes, the next step is to divide the primary headaches based on average monthly frequency of the attacks. Doing so, we divide patients into those of low-tomoderate frequency ( $<15$ headache days per month), or those of high frequency ( $\geq 15$ headache days per month). Second, based on average duration of a typical untreated headache attack, we further classify the headache syndrome as short-duration ( $<4 \mathrm{~h}$ a day) or long-duration (4 h) $[25]$.

The chronic daily headaches of shorter duration (Fig. 3)

As discussed previously, headaches that happen on more than 15 days per month, for less than 4 hours per day, are usually not referred to as CDHs. They belong to a group called the trigeminal autonomic cephalalgias (TACs) [26]. The TACs include the episodic and chronic cluster headache, episodic and chronic paroxysmal hemicrania, short unilateral neuralgiform headache with conjunctival injection and tearing (SUNCT) syndrome, and hypnic headache.

The TACs are characterised by unilateral pain in the trigeminal distribution, with ipsilateral autonomic features. The most common disorder in this family is cluster headache $(\mathrm{CH})$. The pain of $\mathrm{CH}$ is described variously as sharp, boring, drilling, knife-like, piercing or stabbing, in contrast to the pulsating pain of migraine. It usually peaks in 10-15 min but remains excruciatingly intense for an average of 1 hour within a duration range of 15-180 min. During this pain, patients find it difficult to lie still, exhibiting often marked agitation and restlessness, and autonomic features are usually obvious. After an attack, the patient remains exhausted for some time [26, 27].

Like $\mathrm{CH}$, the paroxysmal hemicranias are characterised by unilateral attacks of trigeminal pain and autonomic features. In contrast with $\mathrm{CH}$, the paroxysmal hemicranias have three main features: (1) more frequent (more than five per day); (2) short duration (2-30 min); and (3) absolute response to therapeutic doses of indomethacin. They are rare [28, 29].

The third TAC, SUNCT, is a very rare primary headache. The diagnostic criteria require at least 20 highfrequency attacks (3-200 per day) of unilateral orbital, supraorbital or temporal stabbing or pulsating pain, lasting 5-240 s and accompanied by ipsilateral conjunctival injection and lacrimation. The attacks are characteristically dramatic, with moderately severe pain peaking in intensity within $3 \mathrm{~s}$ and prominent tearing [30].

Hypnic headache is a primary headache disorder of the elderly, characterised by short-lived attacks (typically 30 min) of nocturnal head pain that awakens the patient at a constant time each night, in many cases on more nights

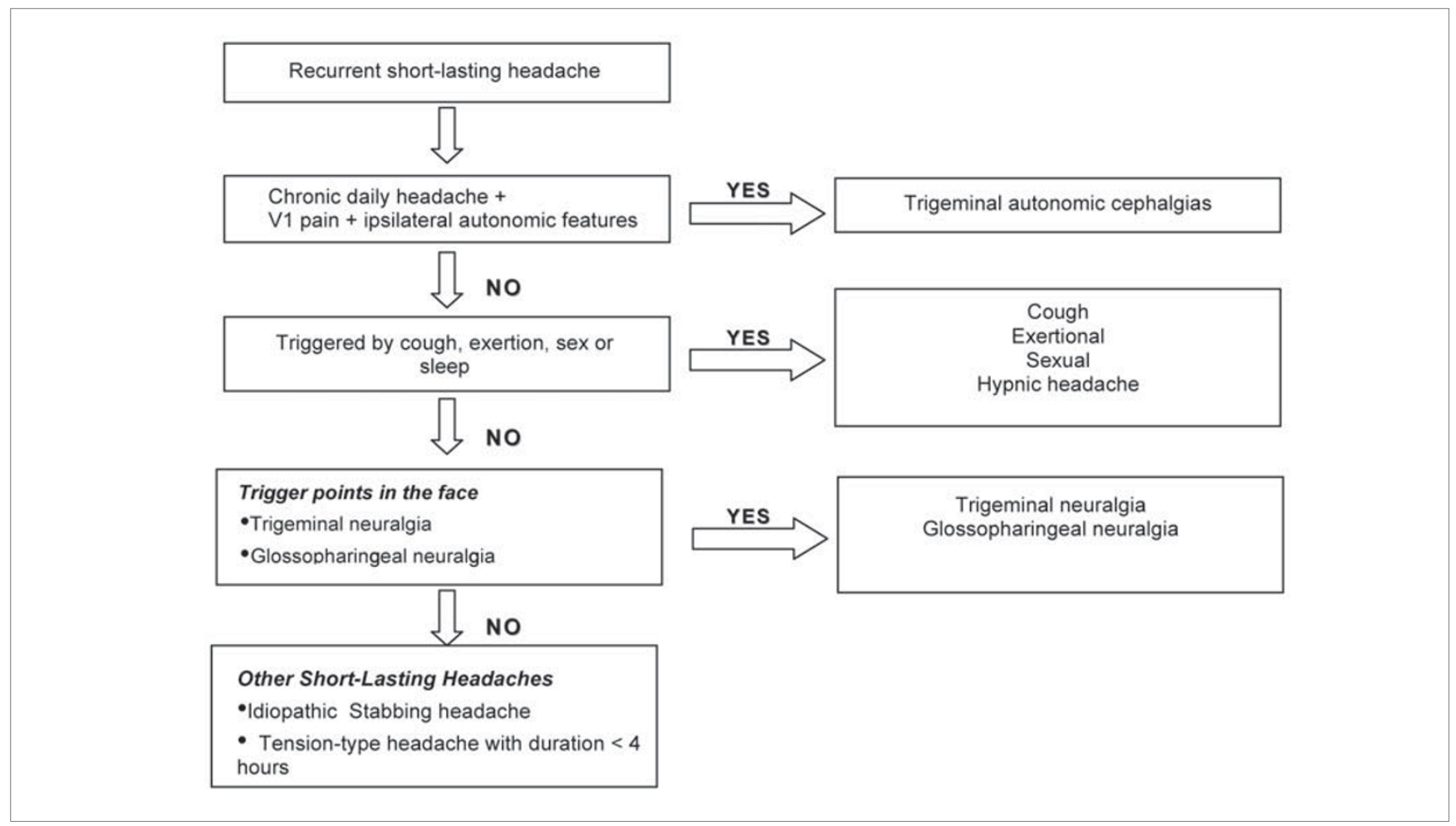

Fig. 3 Short duration headaches 
than not. It does not occur outside sleep. Hypnic headache is usually bilateral (though unilaterality does not exclude the diagnosis) and usually mild to moderate, very different from the unilateral orbital or periorbital knife-like intense pain of cluster headache. Autonomic features are absent $[31,32]$.

Chronic daily headaches of long duration (Fig. 4)

There are four CDHs of long duration, which are discussed here. According to the S-L criteria, all subtypes are subdivided into with or without medication overuse. According to the Second Edition of the International Classification of the Headache Disorders (ICHD-2), a CDH with medication overuse should be classified as medication overuse headache $(\mathrm{MOH})$ regardless of the phenotype. Therefore, in the following section we first describe the four subtypes of the $\mathrm{CDH}$ and then separately describe $\mathrm{MOH}$.

\section{Chronic or transformed migraine}

The terms chronic migraine (CM) and transformed migraine (TM) are frequently used interchangeably, although since the publication of ICHD-2 this is no longer appropriate [33]. Although the two are related, they are different clinical entities with specific definitions.

Patients with TM/CM typically have a past history of migraine. It is more frequent in women with a past history of migraine without aura. Subjects usually report a process of transformation over months or years, and as headache increases in frequency, associated symptoms become less severe and frequent. The process of transformation frequently ends in a pattern of daily or nearly daily headache that resembles chronic tension-type headache, with some attacks of full-migraine superimposed [1-3, 34, 35]. In the clinical setting, migraine transformation most often is related to acute medication overuse, but transformation may occur without overuse. In the more general population, most cases of TM are not related to medication overuse [36]. Multiple risk factors may be involved in these cases.

The S-L criteria identify three potential links to migraine in TM: (A) a prior history of ICHD defined migraine; (B) a period of escalating headache frequency; and $(\mathrm{C})$ concurrent superimposed attacks of migraine that fulfil the IHS criteria. TM is subdivided into with or without medication overuse. If frequent migraine develops de novo in a previously headache-free subject, the diagnosis is new daily persistent headache according to S-L criteria.

The ICHD-2 criteria for CM initially required 15 or more days of migraine per month [33], but these criteria were shown to be too restrictive for clinical practice and research

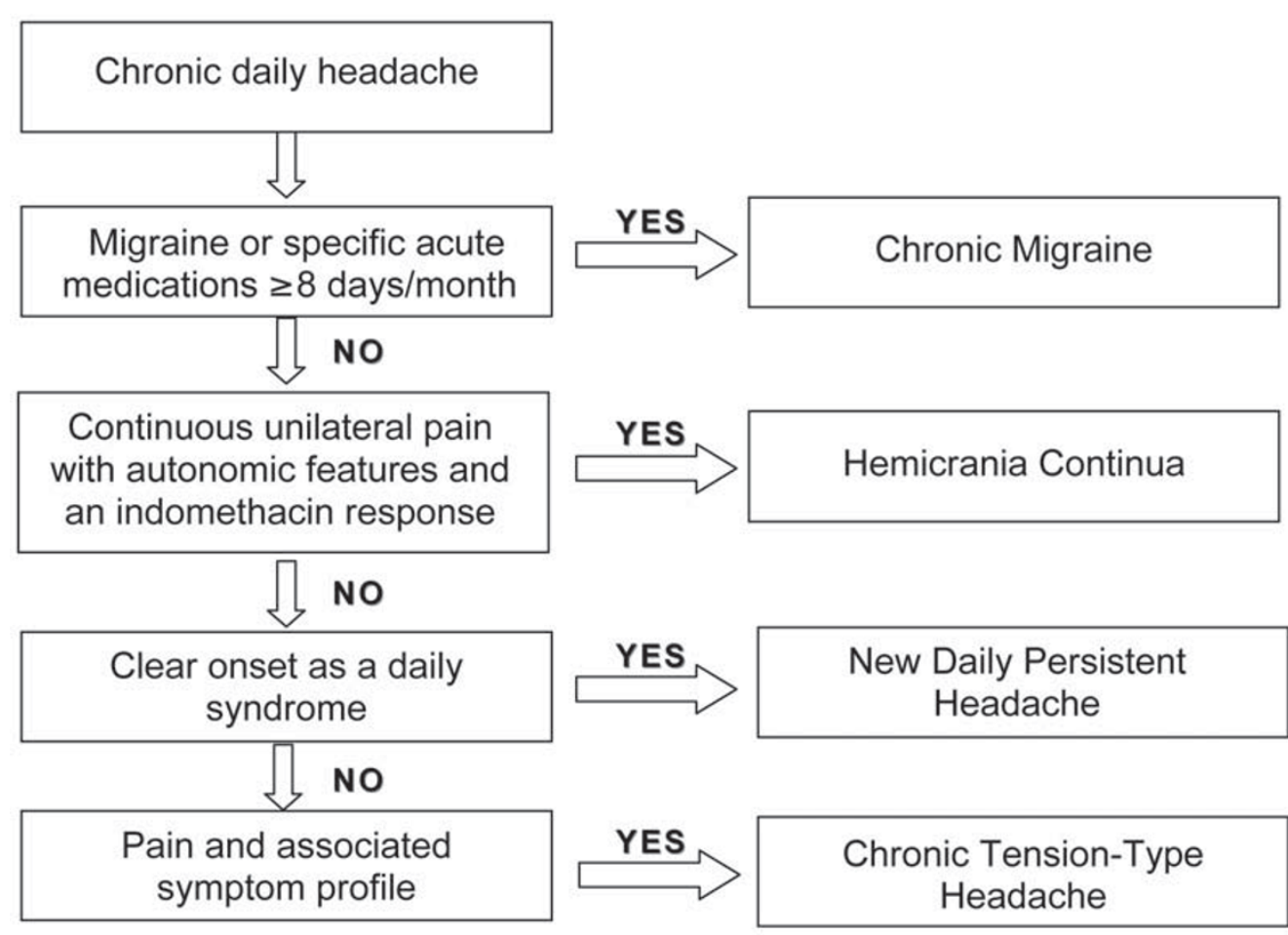

Fig. 4 CDHs of long duration 
[37-41]. As a consequence, the ICHD-2 criteria for CM (ICHD-2R) were recently revised in the Appendix of the classification (Table 3) [42]. CM-R is now defined by CDH plus 8 or more days of migraine as evidenced by headaches that meet ICHD-2 criteria for migraine without aura or headache with response to acute treatment with a migrainespecific medication (triptan or ergotamine compound). As previously stated, if subjects are overusing acute medication they should be classified as having $\mathrm{MOH}[42,44]$.

A recent study compared the criteria for CM-R and TM in a headache specialty clinic. Of 158 patients with TM, just $5.6 \%$ met the old ICHD-2 criteria for CM. According to the ICHD-2R, a total of $92.4 \%$ met the revised criteria for CM $(p<0.001$ vs. ICHD-2), which represents a significant improvement. Subjects with TM and medication overuse should be classified as $\mathrm{MOH}$ (Table 4), and not $\mathrm{CM}+$, according to the ICHD-2R. Nonetheless, the same study assessed the proportion of them who had $\geq 8$ days of migraine per month. Of the 399 individuals with $\mathrm{TM}+$, just $10.2 \%$ could be classified as $\mathrm{CM}+$ in the ICHD-2. However, most $(349,86.9 \%)$ had $\geq 8$ days of migraine per month and could be classified as $\mathrm{MOH}$ and probable $\mathrm{CM}$ in the ICHD-2R $(p<0.001 v s$. ICHD-2). The study concluded that the new criteria for $\mathrm{CM}$ address most of the criticism towards the ICHD-2 and should be adopted in clinical practice and research. In the population where use of specific acute migraine medications is less common, the agreement between ICHD-2R CM and TM may be less robust [43]. $C M / T M$ in adolescents and adults

Differences exist regarding the clinical presentation of TM in adolescents and adults. Most adults with TM have fewer than 15 days of full blown migraine per month and more days of headache resembling tension-type headache than of migraine. In contrast, TM in adolescents is replete with migraine attacks. Medication overuse is more common in adults (84.0\%) than in adolescents (58.9\%) [45].

\section{Phenotype of CM/TM changes over time}

In a recent study of 402 subjects with $\mathrm{TM}$, the proportion of migraine attacks decreased with age (with a proportional increase of tension-type headache attacks), from $71 \%$ below the age of 30 years to $22 \%$ at age 60 or above. It was higher in those with shorter interval from the onset of migraine to the onset of $\mathrm{CDH}$ (less than 5 years, $p=0.003$ ), and in those with a more recent onset of $\mathrm{CDH}$ (less than 6 years, $p<0.0001)$. These findings suggest that CM (15 or more days of migraine per month) is the first stage of migraine chronicity in most patients. Subsequently, the frequency of clearcut migraine attacks diminishes. Thus, CM may be viewed as the earlier stage of TM, and both are different evolutive stages of a chronic migrainous process [46].

The concept that early in the process of transformation

Table 3 Diagnostic criteria for primary chronic daily headaches according to the International Classification of Headache Disorders (2006) Revised Criteria and the Silberstein-Lipton Criteria

\begin{tabular}{|c|c|}
\hline Silberstein-Lipton From 1996 & ICHD-2R \\
\hline Transformed migraine & Chronic migraine \\
\hline A. Daily or almost daily ( $>15$ days a month) head pain for $>1$ month & Diagnostic criteria: \\
\hline B. Average headache duration of $>4$ h per day (if untreated) & Headache on $\geq 15$ days/month for $>3$ months. \\
\hline C. At least one of the following: & Occurring in a patient with at least 5 prior migraine attacks. \\
\hline $\begin{array}{l}\text { 1. History of episodic migraine meeting any IHS criteria 1.1-1.6 } \\
\text { 2. History of increasing headache frequency with decreasing } \\
\text { severity of migrainous features over at least } 3 \text { months }\end{array}$ & $\begin{array}{l}\text { On } \geq 8 \text { days per month, for at least three months, headache fills } \\
\text { criteria } \mathrm{C} 1 \text { and } \mathrm{C} 2\end{array}$ \\
\hline 3. Headache at some time meets IHS criteria for migraine & 1. \\
\hline $1.1-1.6$ other than duration & $\begin{array}{l}\text { Unilateral } \\
\text { Throbbing } \\
\text { Moderate or severe }\end{array}$ \\
\hline $\begin{array}{l}\text { D. Does not meet criteria for new daily persistent headache (4.7) } \\
\text { or hemicrania continua ( } 4.8)\end{array}$ & $\begin{array}{l}\text { Aggravated by physical activity } \\
\text { Nausea and/or vomiting } \\
\text { Photophobia and phonophobia } \\
\text { 2. Treated or relieved with triptans or ergotamine compounds. } \\
\text { D. No medication overuse and not attributable to another causative } \\
\text { disorder. }\end{array}$ \\
\hline
\end{tabular}


most headache days fill criteria for migraine, and as disease evolves, the headache attacks become less typical, has also been supported by an adolescent study, where those with recent-onset $\mathrm{CDH}$ were much more likely to have 15 or more migraine days per month $(74.5 \%$ vs. $25.8 \%$, $p<0.001$ ) [47].

Because the phenotype of CM/TM changes over time, $\mathrm{CM}$ is frequently misdiagnosed as CTTH.

\section{Chronic tension-type headache}

CTTH represents half of the CDH cases found in population studies, but just a small fraction of those found in specialty clinics [48]. It is the only CDH that the ICHD-I considered as a single diagnosis. The criteria remained little changed in the ICHD-II. Despite the fact that ICHD-I and ICHD-II criteria distinguish between episodic and $\mathrm{CTTH}$, the latter headache type remains surprisingly poorly studied. This can be partially explained by the confusion between CTTH and TM with a low frequency of superimposed migraine attacks.

The prevalence of CTTH is markedly lower than that of episodic tension-type headache (ETTH), the most prevalent primary headache disorder. Its 1-year prevalence estimates range from $1.7 \%$ to $2.2 \%$ [48, 49]. The female preponderance of CTTH is greater than that of ETTH but lower than that of migraine. In the USA, the prevalence of CTTH was reported to be 2.8 in women and 1.4 in men, with an overall gender prevalence ratio of 2.0. The prevalence of CTTH increases with age [50].

The distinguishing pain features of CTTH are bilateral location, nonpulsating quality, mild to moderate intensity and lack of aggravation by routine physical activity. The pain is unaccompanied by nausea, although just one of photophobia or phonophobia does not exclude the diagnosis. In other words, CTTH is defined by what it is not (i.e., migraine) [51].

The S-L criteria reserve the diagnosis of CTTH if the $\mathrm{CDH}$ develops abruptly (de novo). It is inferred that this is also true in the ICHD-II criteria, although this feature of evolution is described in the notes but is not part of the formal criteria.

\section{New daily persistent headache}

$\mathrm{CDH}$ may begin without a history of evolution from episodic headache. NDPH is characterised by the relatively abrupt onset of an unremitting primary $\mathrm{CDH}$; i.e., a patient without a previous headache syndrome develops a $\mathrm{CDH}$ that does not remit. The patient's remembering the circumstances, place and date that the headache began is a pathognomonic feature. It is the new onset of this primary daily headache that is the most important feature [52]. The clinical features of the pain are not considered in making the diagnosis, which simply requires absence of history of evolution from migraine or ETTH [1]. The ICHD-II addresses NDPH as a single diagnosis in those with a new-onset CDH that resembles CTTH. A new-onset $\mathrm{CDH}$ with migrainous features cannot be classified as NDPH according to the ICHD-II criteria whereas the S-L classification allows this diagnosis in patients with headache features of migraine or ETTH if the disorder arises abruptly.

Table 4 Classification of the medication overuse subtypes according to the ICHD-2

\begin{tabular}{|c|c|c|}
\hline ICHD-2 code & Diagnosis & Amount of medication \\
\hline 8.1 & Ergotamine overuse headache & Ergotamine intake on $\geq 10$ days per month on a regular basis for $>3$ months \\
\hline 8.2 & Triptan overuse headache & $\begin{array}{l}\text { Triptan intake (any formulation) on } \geq 10 \text { days per month on a regular basis } \\
\text { for }>3 \text { months }\end{array}$ \\
\hline 8.3 & Analgesic overuse headache & $\begin{array}{l}\text { Intake of simple analgesics on } \geq 15 \text { days per month on a regular basis } \\
\text { for }>3 \text { months }\end{array}$ \\
\hline 8.4 & Opioid overuse headache & Opioid intake on $\geq 10$ days per month on a regular basis for $>3$ months \\
\hline 8.5 & Combination analgesic overuse headache & $\begin{array}{l}\text { Intake of combination analgesic medications on } \geq 10 \text { days per month } \\
\text { on a regular basis for }>3 \text { months }\end{array}$ \\
\hline 8.6 & $\begin{array}{l}\mathrm{MOH} \text { attributed to combination } \\
\text { of acute medications }\end{array}$ & $\begin{array}{l}\text { Intake of any combination of ergotamine, triptans, analgesics, and/or } \\
\text { opioids on } \geq 10 \text { days per month on a regular basis for }>3 \text { months } \\
\text { without overuse of any single class }\end{array}$ \\
\hline 8.7 & $\begin{array}{l}\text { Headache attributed to other } \\
\text { medication overuse }\end{array}$ & $\begin{array}{l}\text { Regular overuse for }>3 \text { months of a medication other than those } \\
\text { described above }\end{array}$ \\
\hline 8.8 & Probable $\mathrm{MOH}$ & $\begin{array}{l}\text { Overused medication has not yet been withdrawn or medication overuse } \\
\text { has ceased within the last } 2 \text { months but headache has not so far resolved } \\
\text { or has reverted to its previous pattern }\end{array}$ \\
\hline
\end{tabular}


Hemicrania continua

$\mathrm{HC}$ is probably the most frequently unrecognised primary headache. HC is a chronic, unilateral pain, commonly mistaken for TM $[53,54]$. Both disorders are characterised by chronic unilateral pain with superimposed painful exacerbations. In HC, the painful exacerbations are often associated with ipsilateral autonomic features such as conjunctival injection, lacrimation and ptosis. In TM, exacerbations are more typically accompanied by nausea, photophobia and phonophobia. In addition, patients with HC usually do not have antecedent history of episodic migraine. In TM, attacks increase in frequency over time. If the headaches are longstanding, the patient may not remember how they began. Though pain fluctuates in $\mathrm{HC}$, it does not usually have the morning and end-of-dosing-interval pattern of exacerbations typical of TM. It is advisable to offer to patients with unilateral $\mathrm{CDH}$ a therapeutic trial with indomethacin prior to other intervention (doses of up to $225 \mathrm{mg}$ /day for three to four days).

Medication overuse headache

The ICHD-II classifies MOH under Chapter 8 (headache attributed to a substance or its withdrawal), under the topic
$8.2(\mathrm{MOH}) . \mathrm{MOH}$ is subdivided into seven groups, plus an additional topic for probable $\mathrm{MOH}$ [42]. The diagnostic criteria and the critical amount of consumption of medication are displayed in Table 4. According to the ICHD-II, a diagnosis of $\mathrm{MOH}$ is basically established when two situations are fulfilled: 1. The consumption of acute medication is beyond a critical dose; 2 . There is a $\mathrm{CDH}$.

Although the traditional criteria required demonstration of improvement after detoxification, the revised criteria for $\mathrm{MOH}$ do not. It just requires a $\mathrm{CDH}$ and overuse of medication. Furthermore, the ICHD-II does not suggest that subsidiary investigation is required in all cases but requires that, at least clinically, the provider exclude secondary disorders other than medication overuse.

\section{Conclusions}

The differential diagnosis of $\mathrm{CDH}$ is challenging and requires a systematic approach. Herein we presented an algorithm-based approach to the differential diagnosis of the CDHs, which should help physicians interested in headache to move forward quickly and safely when assessing patients with daily or almost daily headaches.

\section{References}

1. Silberstein SD, Lipton RB, Sliwinski M (1996) Classification of daily and near-daily headaches: field trial of revised IHS criteria. Neurology 47:871-875

2. Spierings EL, Ranke AH, Schroevers M, Honkoop PC (2000) Chronic daily headache: a time perspective. Headache 40:306-310

3. Welch KM, Goadsby PJ (2002) Chronic daily headache: nosology and pathophysiology. Curr Opin Neurol 15:287-295

4. Scher AI, Stewart WF, Liberman J, Lipton RB (1998) Prevalence of frequent headache in a population sample. Headache 38:497-506

5. Castillo J, Muñoz P, Guitera V, Pascual J (1999) Epidemiology of chronic daily headache in the general population. Headache 39:190-196
6. Evans R, Purdy A (2006) Identification or exclusion of secondary headaches. In: Lipton RB, Bigal ME (eds) Migraine and other headache disorders. Informa Healthcare, New York, pp 131-144

7. Lipton RB, Silberstein SD, Saper JR et al (2003) Why headache treatment fails. Neurology 60:1064-1070

8. Dodick DW, Wijdicks EF (1998) Pituitary apoplexy presenting as a thunderclap headache. Neurology 50:510-511

9. Forsyth PA, Posner JB (1993) Headaches in patients with brain tumors: a study of 111 patients. Neurology 43:1678-1683

10. Lawson W, Reino AJ (1997) Isolated sphenoid sinus disease: an analysis of 132 cases. Laryngoscope 107:1590-1595
11. Edmeads J (1997) Headaches in older people. How are they different in this age-group? Postgrad Med 101:91-94

12. Ameri A, Bousser MG (1992) Cerebral venous thrombosis. Neurol Clin 10:87-111

13. Lay CL, Campbell JK, Mokri B (1997) Low cerebrospinal fluid pressure headache. In: Goadsby P, Silberstein SD (eds) Blue books of practical neurology: headache. ButterworthHeinemann, Boston, pp 355-368

14. Sands GH, Newman LC, Lipton RB (1991) Cough, exertion and other miscellaneous headaches. Med Clin North Am 75:733-748

15. Edmeads JG (2001) Disorders of the neck: cervicogenic headache. In: Silberstein SD, Lipton RB, Dalessio DJ (eds) Wolff's headache and other head pain. Oxford University Press, New York, pp 447-458 
16. Lipton RB, Lowenkopf T, Bajwa ZH et al (1997) Cardiac cephalgia: a treatable form of exertional headache. Neurology 49:813-816

17. Marks DR, Rapoport AM (1997) Practical evaluation and diagnosis of headache. Semin Neurol 7:307-312

18. Evers S, Wibbeke B, Reichelt D et al (2000) The impact of HIV infection on primary headache. Unexpected findings from retrospective, cross-section$\mathrm{al}$, and prospective analyses. Pain 85:191-200

19. Solomon S (2001) Posttraumatic headache. Med Clin North Am 85:987-996

20. Andermann E, Andermann FA (1987) Migraine-epilepsy relationships: epidemiological and genetic aspects. In: Andermann FA, Lugaresi E (eds) Migraine and epilepsy. Butterworths, Boston, pp 281-291

21. Graff-Radford S (2001) Disorders of the mouth and teeth. In: Silberstein SD, Lipton RB, Dalessio DJ (eds) Wolff's headache and other head pain. Oxford University Press, New York, pp 475-493

22. Martin TJ, Soyka D (1993) Ocular causes of headache. In: Olesen J, Tfelt-Hansen P, Welch KMA (eds) The headaches. Raven Press, New York, p 748

23. Cady RK, Schreiber CP (2002) Sinus headache or migraine? Considerations in making a differential diagnosis. Neurology 58[Suppl 6]:10-14

24. Wenig BM (1999) Nasopharyngeal carcinoma. Ann Diagn Pathol 3:374-385

25. Lipton RB, Bigal ME (2006) Differential diagnosis of primary headaches. An algorithm based approach. In: Lipton RB, Bigal ME (eds) Migraine and other headache disorders. Informa Healthcare, New York, pp 145-154

26. Goadsby PJ, Lipton RB (1997) A review of paroxysmal hemicranias, SUNCT syndrome and other short-lasting headaches with autonomic features, including new cases. Brain 120:193-209

27. Dodick DW, Rozen TD, Goadsby PJ, Silberstein SD (2000) Cluster headache. Cephalalgia 20:787-803

28. Antonaci F, Sjaastad O (1989) Chronic paroxysmal hemicrania $(\mathrm{CPH})$ : a review of the clinical manifestations. Headache 29:648-656
29. Sjaastad O, Dale I (1974) Evidence for a new (?) treatable headache entity. Headache 14:105-108

30. Pareja JA, Sjaastad O (1997) SUNCT syndrome. A clinical review. Headache 37:195-202

31. Newman LC, Lipton RB, Solomon S (1990) The hypnic headache syndrome: a benign headache disorder of the elderly. Neurology 40:1904-1905

32. Dodick DW, Mosek AC, Campbell IK (1998) The hypnic ("alarm clock") headache syndrome. Cephalalgia 18:152-156

33. Headache Classification Committee of the International Headache Society (2004) The International Classification of Headache Disorders. Cephalalgia 24[Suppl 1]:1-160

34. Mathew NT (1993) Transformed migraine. Cephalalgia 13:78-83

35. Saper JR (1982) The mixed headache syndrome: a new perspective. Headache 22:284-286

36. Scher AI, Stewart WF, Ricci JA, Lipton RB (2003) Factors associated with the onset and remission of chronic daily headache in a population-based study. Pain 106:81-89

37. Bigal ME, Tepper SJ, Sheftell FD et al (2004) Chronic daily headache: correlation between the 2004 and the 1988 International Headache Society diagnostic criteria. Headache 44:684-691

38. Bigal ME, Tepper SJ, Sheftell FD et al (2006) Field testing alternative criteria for chronic migraine. Cephalalgia 26:477-482

39. Sancisi E, Cevoli S, Pierangeli G et al (2007) Application of ICHD-II and revised diagnostic criteria to patients with chronic daily headache. Neurol Sci 28:2-8

40. Sarchielli P, Alberti A, Pedini M, Gallai V (2005) ICHD 2nd Edition: Some considerations on the application of criteria for primary headache. Cephalalgia 25:157-160

41. Lima MM, Padula NA, Santos LC et al (2005) Critical analysis of the international classification of headache disorders diagnostic criteria (ICHD I-1988) and (ICHD II-2004), for migraine in children and adolescents. Cephalalgia 25:1042-1047
42. Headache Classification Committee; Olesen J, Bousser MG, Diener HC et al (2006) New appendix criteria open for a broader concept of chronic migraine. Cephalalgia 26:742-746

43. Bigal M, Rapoport A, Sheftell F et al (2007) The International Classification of Headache Disorders revised criteria for chronic migraine-field testing in a headache specialty clinic. Cephalalgia 27:230-234

44. Silberstein SD, Olesen J, Bousser MG et al; International Headache Society (2005) The International Classification of Headache Disorders, 2nd Edition (ICHD-II) - revision of criteria for 8.2 Medication-overuse headache. Cephalalgia 25:460-465

45. Bigal ME, Rapoport AM, Tepper SJ et al (2005) The classification of chronic daily headache in adolescents - a comparison between the second edition of the international classification of headache disorders and alternative diagnostic criteria. Headache 45:582-589

46. Bigal ME, Rapoport AM, Sheftell FD et al (2005) Chronic migraine is an earlier stage of transformed migraine in adults. Neurology 65:1556-1561

47. Bigal ME, Lipton RB, Tepper SJ et al (2004) Primary chronic daily headache and its subtypes in adolescents and adults. Neurology 63:843-847

48. Rasmussen BK, Olesen J (1994) Epidemiology of migraine and tensiontype headache. Curr Opin Neurol 7:264-271

49. Lavados PM, Tenhamm E (1998) Epidemiology of tension-type headache in Santiago, Chile: a prevalence study. Cephalalgia 18:552-558

50. Schwartz BS, Stewart WF, Simon D, Lipton RB (1998) Epidemiology of tension-type headache. JAMA 279:381-383

51. Sheftell FD, Bigal ME (2006) Medication overuse headache. Continuum 12:147-163

52. Rozen TD (2003) New daily persistent headache. Curr Pain Headache Rep 7:218-223

53. Sjaastad O, Spierings EL (1984) Hemicrania continua: another headache absolutely responsive to indomethacin. Cephalalgia 4:65-70

54. Bordini C, Antonaci F, Stovner LJ et al (1991) "Hemicrania continua": a clinical review. Headache 31:20-26 